\title{
MARKETING RELACIONAL COMO ESTRATEGIA DE LOS NEGOCIOS DEL PERÚ
}

\author{
RELATIONSHIP MARKETING AND BUSINESS STRATEGY OF PERÚ
}

\author{
Ricardo Barrón Araoz * \\ Docente Principal de la Facultad de Ciencias Contables - UNMSM \\ [Recepción: Setiembre de 2011/ Conformidad: Noviembre 2011]
}

\section{RESUMEN}

Actualmente, gran cantidad de empresas en el mundo en el rubro comercial están desarrollando modelos de negocio basados en marketing relacional; ello se explica en que el enfoque transaccional era progresivamente incapaz de dar respuestas plenamente satisfactorias a los problemas comerciales contemporáneos. $\mathrm{Al}$ mismo tiempo, han surgido nuevas posibilidades técnicas, especialmente en el campo de las tecnologías de la información y comunicaciones, que han abierto nuevos horizontes hacia un nuevo tipo de marketing: el marketing relacional

Son muy pocas las empresas que conocen las técnicas y estrategias dirigidas a retener o mejorar la rentabilidad de sus clientes actuales; algo que hoy en día es considerado mucho más importante.

Sin embargo el marketing relacional o CRM sigue siendo un tema bastante abandonado por el común de las empresas en el Perú.

No es extraño que uno de los problemas más frecuentes en las empresas sea la falta de consistencia entre los empleados al momento de interactuar con sus clientes.

El presente artículo busca destacar la importancia de desarrollar un modelo de gestión de las relaciones con los clientes basado en el marketing relacional; así como evaluar la actual posición de las empresas peruanas en la economía internacional basado en la aplicación del CRM.

\section{Palabras Clave}

Marketing Relacional, atención al cliente, Seducción al cliente, Posicionamiento, CRM.

\begin{abstract}
Currently, many companies in the world in the line of business are developing business models based on relationship marketing, it is explained that the transactional approach was increasingly unable to provide fully satisfactory answers to contemporary business problems. At the same time has created new technical possibilities, especially in the field of information technology and communications, which have opened new horizons to a new type of marketing: relationship marketing.

Very few companies have the skills and strategies to retain or improve the profitability of existing customers, something that today is considered much more important.

However, the relationship marketing or CRM remains a rather neglected by ordinary companies in Peru.

No wonder that one of the most common problems in business is the lack of consistency among employees when interacting with customers.

This article seeks to highlight the importance of developing a model for managing customer relationships based on relationship marketing, as well as assess the current position of Peruvian companies in the international economy based on the application of CRM.
\end{abstract}

\section{Keywords}

Relationship Marketing, Customer Care, Seduction Customer, Positioning, CRM.

\footnotetext{
* Doctor en Ciencias Contables y Empresariales - UNMSM, Docente Investigador de la Facultad de Ciencias Contables -UNMSM. E-mail: ricardo.20octubre@hotmail.com
} 


\section{INTRODUCCIÓN}

El marketing relacional en su función principal consiste en establecer la interacción por el cliente, calificado por Carlzon como activo más importante de la Empresa, por lo tanto hay la necesidad de mantener el contacto permanente con los clientes.

Según la revista "Forutne", en análisis de las 10 empresas con crecimiento rápido en EE.UU. se obtienen dos razones de su éxito:

1. Poner al cliente en primer lugar, escuchándole, comprendiéndole y sirviéndole.

2. Moverse con rapidez y adaptabilidad

Antiguamente las organizaciones empresariales en general no sabían valorar a sus clientes, pero gracias a la expansión de la economía y con el crecimiento de los mercados en las que se ofrecen diversidad de productos cada vez con mayores bondades, originando agresivas competencias entre los ofertantes, situación en la que juega un papel preponderante el cliente como el activo mas importante de los negocios en general., despierta entre los fabricantes y comerciantes el interés en el cuidado a sus clientes actuales.

El aspecto más importante del marketing relacional es la interacción con el cliente. No sólo se busca el contacto con los clientes para darles información acerca de nuestros productos, sino también para recibir de ellos la información necesaria que permita a la empresa satisfacerlos cada vez mejor sus exigencias, sus gustos sus necesidades; de este modo, el marketing no se ve aislado en la empresa, pues otras áreas como la facturación, despachos, créditos, cobranzas, etc., se convierte en fuentes confiables de lo que el cliente desea.

\section{DESARROLLO DE UN MODELO DE MARKETING RELACIONAL}

El desarrollo de un modelo de marketing relacional; considera el desarrollo de estrategias que permitan obtener clientes leales y satisfechos a lo largo del tiempo, en ese sentido se ha considerado basar este artículo en las estrategias que formula Vilaginés: - La estrategia del marketing relacional como cuarto tipo de obtención de una ventaja competitiva sostenible.

La estrategia consiste en determinar un sistema de objetivos, políticas y planes de acción, claramente especificados, que configuran una orientación, como la movilización de recursos para aprovechar las oportunidades identificadas y disminuir los riesgos futuros.

La dirección estratégica sigue un proceso laborioso para recoger todas las informaciones básicas sobre la competitividad de la empresa en los distintos mercados en las que participa, frente a los competidores y el entorno. Por ello la estrategia nos permite concentrarnos en dos áreas básicas esenciales: La decisión de inversión en producto / mercado, que define el alcance de la estrategia en términos de productos y mercados, $y$ la asignación de las inversiones en ellos.

El desarrollo de una ventaja competitiva sostenible para competir en dichos mercados, que determina la forma de competir en función de las capacidades primordiales, los objetivos arcados y los recursos asignados. La obtención de una ventaja competitiva sostenible es, tal como indica M. Porter, la base fundamental de unos resultados por encima de la media: "La ventaja competitiva surge del valor que la empresa es capaz de crear para sus compradores que excede el costo de crearlos. El valor es lo que los compradores están dispuestos a pagar, y el valor superior se obtiene por la oferta de precios 
inferiores a los competidores para beneficios equivalentes, o de proveer beneficios únicos que compensan más que los precios superiores. De acuerdo a lo expuesto por M. Porter, tenemos que satisfacer las necesidades y deseos de nuestros clientes mejor que los demás. La ventaja competitiva - de acuerdo con Porter - ha sido clasificada hasta el momento en tres tipos: el costo más bajo, una oferta diferenciada y la de enfoque o nicho protegido. Entre las características principales de cada una de ellas, tenemos:

\section{Menor costo}

La estrategia de menor costo va asociada normalmente con estrategias tendentes a alcanzar un volumen elevado por obtención de economías de escala. La orientación está dirigida hacia la productividad, la eficiencia, y la reducción de costos. Otras formas de ventaja pueden ser a través de acceso ventajoso a materias primas o procedimientos tecnológicos.

\section{El riesgo}

Presente en la estrategia específica de volumen para obtener economías de escala es que se produzcan cambios importantes en el entorno de mercado, que hagan infranqueables las rigideces incorporadas a la estrategia de volumen.

\section{Estrategia diferenciada,}

Es la que intentan adoptar un mayor número de empresas, aunque muchas caen en una posición poco clara, $y$, por tanto, débil.

\section{Ocupación de un nicho protegido}

La empresa tiene que tener las capacidades y recursos para servir al nicho efectivamente. La empresa debe constituir un fondo de co- mercio de clientes suficientes para defenderse contra cualquier compartidor importante.

Viaginés enmarca al marketing relacional como una estrategia para la obtención de nuestros clientes, sostenible, en la destaca la importancia de satisfacer las necesidades de nuestros clientes mejor que la competencia, basado en la segmentación por sectores (enfoque de arriba abajo), donde el cliente aparece como resultado de un uso de instrumentos intermedios de producto / mercado y forma parte de una masa en la cual se presume homogeneidad de grupo; sin embargo visto como nichos (enfoque de abajo hacia arriba) el tiende a individualizarse y a ende cubre necesidades específicas.

La gestión de la base de clientes como enfoque fundamental de la estrategia de marketing relacional Joseph Vilaginés señala que la estrategia se encuentra enfocada a dos puntos: La relación establecida entre la empresa y sus clientes crea unos vínculos de unión que sirven de escudo frente a la entrada de nuevos competidores, y, el conocimiento íntimo de los clientes permitirá a la empresa reaccionar a tiempo y evitar la desaparición de sus nichos. El valor del cliente es la base para un cambio de enfoque en la estrategia de la empresa.

\section{VISION A LARGO PLAZO}

$\mathrm{Al}$ empresario no le debe interesar las ventas de hoy, su preocupación debe ser maximizar el valor presenta neto de las transacciones futuras de un cliente.

Buscar ampliar el número de relaciones que se puede tener con un cliente en vez del número de clientes. Al dejar de buscar nuevos clientes se optimizan los recursos. Lo aconsejable es tratar bien a los que ya se tiene y afianzar la relación con ellos. Recordar el Principio de Pareto 20-80. 


\section{MANEJAR LA BASE DATOS DEL CLIENTE}

Se trata del manejo de base de datos sofisticado de clientes, no una simple recopilación de datos personales como: el nombre, la dirección, teléfono, ocupación, estado civil, número de hijos, Clubes a los que pertenece etc, si no, una verdadera comunicación empresa - cliente.

La base de datos utilizado, permite la flexibilidad necesaria para desarrollar nuevas propuestas de valor agregado, debido a que contienen información directa y al día de nuestros clientes y pueden darnos una aproximación de lo que sucede en el mercado general.

La base de datos de los clientes, no constituyen ninguna información si es que no se les procesa para que pueda ser de utilidad a nuestros fines; o sea, que debemos de hacer uso de ella y demostrarle al cliente que efectivamente estamos pendientes de él y si pedimos lealtad, es porque nosotros también podemos ofrecerles lealtad. Al dejar de buscar nuevos clientes, se optimicen los recursos, lo aconsejable es tratar bien a los clientes antiguos de ese modo afianzar la relación con los que ya se tiene. Recordar la relación conocida en el mundo comercial como principio de Pareto, la del 20-80 que alude que el $20 \%$ de nuestros clientes hacen el $80 \%$ de la facturación.

Carlzón dice: "Para aquellos momentos de verdad tenemos que dar la responsabilidad de generar ideas, decisiones y acciones estratégicas a los empleados y trabajadores para que en ese momento de la verdad se conviertan en empleados de primera línea.

\section{EL COSTO DEL CRM}

Dependerá de cómo se maneja los recursos, pues primeramente tenemos que ser capaces de identificar que tiene valor para el cliente $y$ que no, para que de esa forma eliminar todo lo que termina sobrando.

Debemos evitar aumentar costos en aquellas cosas que nuestros clientes no valoran y reorientar el uso de nuestros recursos aumentando el valor de los productos o servicios que ofrecemos a nuestros clientes.

\section{REDEFINIR EL CONCEPTO SOBRE NUESTROS CLIENTES.}

En el marco del tema que comprende el Marketing Relacional, que trata exclusivamente de Interrelación entre empresa- cliente, conviene ampliar el gran aporte Jan Carlzon Jan Carlzon, profesor de una importante universidad norteamericana, acuñó la frase de " "Momentos de Verdad" , obra que trata de "Atención al cliente", una autoridad mundial en temas de atención al cliente.

Carlzon cuenta su experiencia exitosa en su gestión frente a la empresa Scandinavian Airlines ( SAS), que en plena crisis de la década de los 80 , pudo convertir el SAS en una de las empresas más rentables en el sector, por la calidad de servicios. De esta experiencia formula el siguiente postulado: "Servicio al cliente como una ventaja competitiva"

Cada cliente tiene sus deseos, la necesidades diferente que otras personas en el mismo mercado-producto, cada consumidor es un mundo diferente, cada vez quiere los productos a su medida, los clientes desean ser tratados como individuos. Y para ello el Marketing relacional: Defiende la necesidad de desarrollar una estrategia empresarial en torno al cliente, creando y explotando la relación con él de forma rentable.

Ofrece un esquema formal que ayuda a manejar la gestión comercial de la empresa, ofreciendo una visión coherente común, en base a una perspectiva panorámica amplia a través de la relación con sus clientes. 
La aportación más importante es la de ver la empresa como una suma sinérgica de clientes. El análisis de la estrategia competitiva de la empresa - aun contemplando los elementos del entorno y de la competencia donde actúa- se realiza desde la perspectiva del cliente, tanto en el área de programas comerciales, como en el de factores competitivos o de creación del valor.

De allí la gran importancia de abordar en este artículo sosteniendo al Marketing relacional como un nuevo paradigma de las actuales organizaciones.

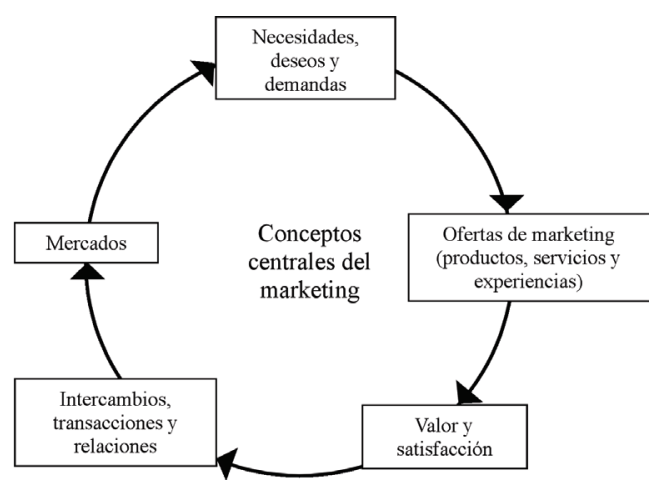

\section{CARACTERÍSTICAS DEL MARKETING RELACIONAL}

La interactividad. El cliente toma cuando quiere la iniciativa del contacto, como receptor y como emisor de comunicaciones.

La direccionalidad de las acciones y su correspondiente personalización. Las empresas pueden dirigir mensajes distintos a cada cliente, adecuados precisamente a las circunstancias de ese cliente.

La memoria. El registro en memoria de la identidad, datos, características, preferencias y detalles de las interacciones anteriormente mantenidas con cada cliente.

La receptividad. Las empresas deben hablar menos y escuchar más. Y permitir que sea el cliente quien decida si quiere o no mantener una relación, quien defina el modo de comu- nicación, y si quiere mantenerla o terminarla.

Orientados al cliente. Poner más énfasis en una organización comercial compuesta por consumer managers y no de product managers.

La empresa debe centrarse más en el consumidor, sus necesidades y los procesos que sigue para satisfacerlas.

- Poner más énfasis en la "participación por cliente" que en la "participación de mercado".

- La empresa debe estar dispuesta a tratar de manera distinta a sus clientes más valiosos. Sofisticación en la segmentación y clasificación de clientes

\section{LA TECNOLOGÍA COMO INSTRUMENTO DEL MARKETING RELACIONAL}

Internet es un instrumento maravilloso, cuyas potencialidades siguen ampliándose y desarrollándose al tiempo que las vamos descubriendo.

En consecuencia, las observaciones que podemos hacer en estos momentos son primitivas, sobre la marcha, y probablemente muchos menores de las que irán emergiendo con el tiempo y con las nuevas innovaciones tecnológicas.

Además, es un instrumento muy flexible, por lo que distintas empresas pueden descubrir potencialidades distintas y peculiares que se apliquen de manera especialmente adecuada a sus circunstancias comerciales particulares.

Pero hay que saber utilizar este instrumento sin olvidar que, según Sisodia y Wolfe, su función más productiva no debe ser la de sustituir las facultades humanas, sino la de amplificarlas y potenciarlas. Pero lo que ya está claro es que la disponibilidad de Internet y del correo electrónico facilita enormemente el diseñar y poner en práctica estrategias de marketing relacional. 
Para ilustrarlo, me serviré de un ejemplo Concreto: El caso de HP -un ejemplo concreto de cómo Internet permite establecer con el cliente una relación personalizada que beneficia a la empresa- demuestra las posibilidades que ofrece esta tecnología. Su experiencia nos confirma que el verdadero reto de cada empresa es saber descubrir y poner en práctica los mecanismos o instrumentos informáticos concretos y el contenido adecuado para lograr fortalecer las relaciones con sus clientes, al tiempo que erige barreras protectoras de su base de clientes frente a los ataques de la competencia.

Pero todo ello sin olvidar que, como dice Barnes «una relación con un cliente no existe hasta que el cliente reconoce que existe». $\mathrm{O}$, como señala Ahlert, «para construir una relación es preciso interaccionar con alguien de manera íntima, durante un largo período de tiempo». Y para ello, es imprescindible que la empresa actúe de manera técnica y éticamente correcta, para lograr que el cliente la considere digna de confianza. Es preciso insistir en que el énfasis debe ponerse en desarrollar unas relaciones generadoras de valor para ambas partes, y no sólo, ni prioritariamente, en la reducción de costes.

Asimismo, como nos advierten Sisodia y Wolfe, «las relaciones altamente vinculantes y emocionalmente satisfactorias requieren la presencia periódica de seres humanos. Si la prestación es impersonal y mecanizada, volveremos a caer en el marketing transaccional».

Finalmente, hemos de tener en cuenta que todo esto no ha hecho más que empezar. Como señalaba recientemente Bill Gates: «A pesar de todas estas maravillas, la tecnología está en el año 2001 donde estaba aproximadamente la fabricación de automóviles cuando Henry Ford lanzó su modelo $\mathrm{T} \gg$.

\section{CONCLUSIONES}

- Conforme hemos decidido el Marketing relacional es paradigma de marketing general.

- Al fidelizar a nuestros clientes actuales encontramos la rentabilidad de la empresa, porque buscando clientes nuevos incu- rrimos a costos altos. La relación entre un cliente antiguo y nuevo es de uno a cinco.

- La aplicación del Marketing Relacional o CRM, ejecutada de manera planificada y organizada ayudarán a conseguir los objetivos de la empresa, una rentabilidad a largo plazo y gozar de una clientela que le dé ese sustento. Podrán ser adoptados, adaptados y modificados, según sea el caso de cada empresa. Es importante darse cuenta que el nuevo milenio con los adelantos tecnológicos en todos los campos, ofrece un verdadero reto para las empresas en crear nuevas estrategias de fidelización de sus clientes.

- El Marketing Relacional abre la posibilidad de aplicar está estrategia de diferenciación para la fidelización de los clientes.

- El potencial de desarrollo en las empresas está en la atención que le dé a sus clientes, utilizando la combinación de las estrategias del Marketing Relacional basado en la relación de la tecnología de base de datos y el marketing de relacionales con el cliente - CRM - que vincula la información del cliente con los datos de transacción para recoger y unir los fragmentos de conocimiento sobre preferencias, motivaciones $y$ activadores de compra del cliente e impulsar ese conocimiento a través de la organización para tomar decisiones de negocios centradas en el cliente.

\section{REFERENCIAS BIBLIOGRÁFICAS}

1. KOTLER, Philip, ARMSTRONG, Gary, (2006), Marketing 10 Ed. Pirámide Hall, Madrid-España.

2. CZINKOTA Michael R. ROBINSON, Likka A. Marketing Internacional $7^{\circ}$ Ed. (2004) Thomson, Argentina.

3. Barrón Araoz Ricardo (2000) Ed. Herrera Asociados - Lima

4. Aportes de clase del Profesor Ricardo Barrón Araoz

5. José Luis Nuevo, Profesor de Marketing JESE (2005) - Madrid. 